\title{
A SURVEY OF THE CLINICAL WORK OF THE PSYCHIATRIC SERVICES BASED ON BRITISH MILITARY HOSPITAL, SINGAPORE, $1969-1970$
}

\author{
Captain D. W. F. GLEN, M.B., Ch.B., R.A.M.C. \\ Royal Victoria Hospital, Netley
}

SUMMARY: A report of the clinical work performed by the psychiatric service, based on the British Military Hospital (B.M.H.), Singapore, is presented for the period June 1969 - June 1970. This was, at the time, thought to be the penultimate year of the British presence in the area, and this paper is intended to convey the quantity and quality of the clinical work done by the department, before the " run down" radically reduced the service population. The survey is presented in three parts, the Out-patient, the In-patient and the Child Guidance services. The Psychiatric service provided an in and out-patient facility for adults and a predominantly out-patient service for children. If any of the latter required admission to hospital they were accommodated in the Paediatric Ward. The population served consisted of service men, of all three Services, including locally enlisted men and their dependants. In addition it also covered civilians employed by the British Government within the area. In geographical terms the department's area included Singapore Island, West and East Malaysia, Gan and Nepal.

\section{Introduction}

During the period under review there was a marked decrease in the service population of West Malaysia and a relatively small fall in that of Singapore. There was a degree of redistribution of population between these two areas as Commonwealth units moved into Singapore in the last six months of the year.

"P Division" in the British Military Hospital, Singapore, provided a male ward of 20 beds and a female ward of 8 beds. It also had three consulting rooms, two airconditioned; a waiting area, a ward office and a Wardmaster's office. The Child Guidance Centre was located one mile from the hospital. Facilities were made available for outpatient clinics once weekly at Royal Air Force, Changi and Her Majesty's Ship " Terror " and once monthly at Penang. Until December 1969 a once monthly clinic was also held at the British Military Hospital, Terendak.

The staff of the department consisted of two psychiatrists, one with a special interest in children, and a trainee. The nursing complement was two Q.A.R.A.N.C. Sisters, both Registered Mental Nurses (R.M.N.), and fourteen male nurses (seven R.M.N.), plus six locally employed female ward assistants.

The Child Guidance "team" was made up of one psychiatrist, an educational psychologist and a qualified Psychiatric Social Worker. This team not only worked in Singapore but also travelled at regular intervals to Penang, and outside the catchment area to Hong Kong.

"P Division" was the only ward in the hospital which retained the right to refuse admission to patients referred by medical officers. The criteria for admission were, 
$1 \mathrm{mg}$.

Tablets $1 \mathrm{mg}$. permit easy adjustment of dosage when initiating treatment

\section{$2 \mathrm{mg}$.}

'Spansule' Capsules 2mg. provide an exceptionally convenient dosage unit for routine use

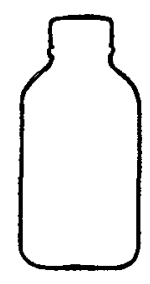

Syrup $1 \mathrm{mg} . / 5 \mathrm{ml}$.

A palatable Syrup to meet the need for liquid therapy whenever this is preferred by either doctor or patient

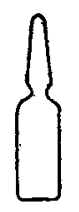

Ampoules $1 \mathrm{mg} . / 1 \mathrm{ml}$.

For rapid effect in the extremely agitated or disturbed psychoneurotic patient

\section{anxiety states respond swiftly to the true tranquillizing effect of}

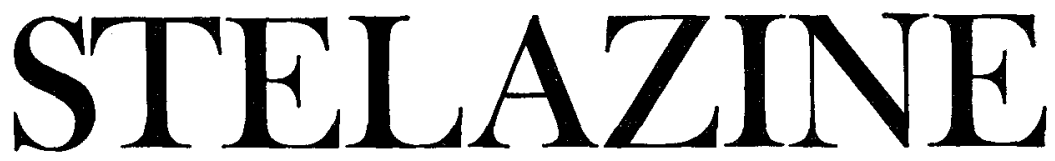

Literature giving full prescribing information is available on request.

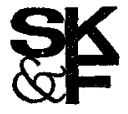

SMITH KLINE \& FRENCH LABORATORIES LTD. WELWYN GARDEN CITY, HERTFORDSHIRE 'Stelazine' (brand of trifluoperazine dihydrochloride) and 'Spansule' are trade marks SSZL: PA39AN 


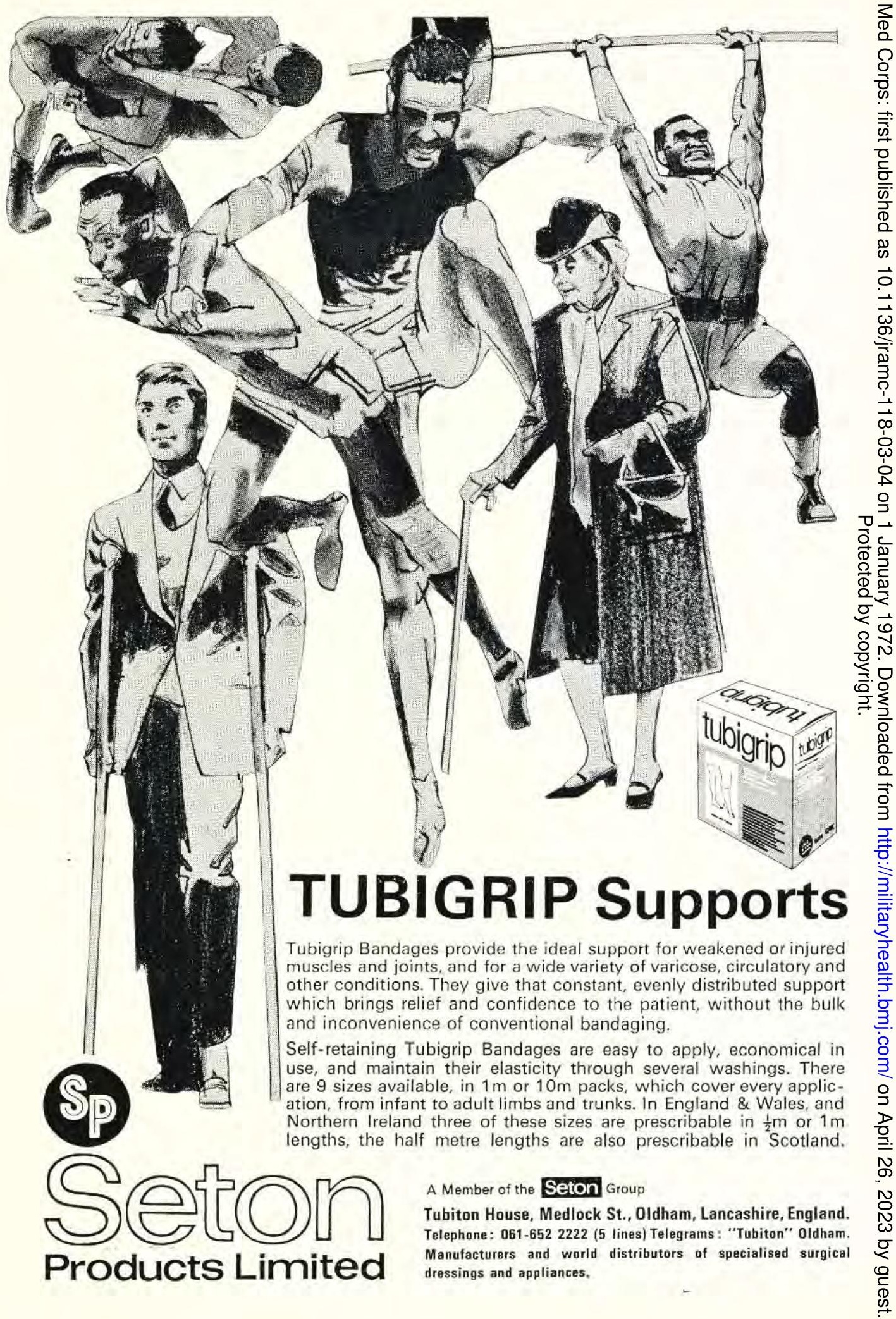


making allowance, in the case of males particularly, for certain aspects of service environment, as close to those appertaining in civilian life as possible. The wards were seen as the correct arena for the treatment of acute psychiatric illness; for observation, and elucidation of the diagnosis and for intensive care or psychotherapy. For every in-patient a decision had to be made as to whether the long term prognosis of their condition required that they should be evacuated, under medical supervision, to the United Kingdom for further management.

The wards had facilities for the full range of investigations and treatment. The greatest weakness in the therapeutic armoury lay in the very limited range of occupational therapy available.

In the out-patient field the emphasis was laid on maintaining the patient in the community. The department took a special interest in the Marriage Guidance Service and referred suitable patients to it. Close contacts were also maintained with S.S.A.F.A. and the Naval Welfare organisation. An attempt was made, not always successfully, to maintain communications between these agencies and the department when one or more were involved with one particular case.

\section{Method}

The material presented was basically derived, retrospectively, from the in and out-patient records held in the department. Where necessary this material has been added to and amplified by notes kept by the writer and by perusal of individual patient's notes.

Population figures were obtained from Headquarters, Far East Land Forces and the rates presented below have been calculated on the population recorded for December 1969. In calculations involving Naval personnel, patients derived from ships not based in Singapore have been excluded. In the in-patient study patients in transit to the United Kingdom from Hong Kong have been excluded from calculation of admission rates.

\section{Numbers and rates}

\section{The out-patient service}

Five-hundred and sixty patients were seen as out-patients during the year. Fourhundred and eleven, 73 per cent were new patients. This total includes those patients sent up as possible admissions and assessed first by out-patient interview. Seventeen per cent were already out-patients at the beginning of the survey year. Nine per cent were discharged in-patients who were not assessed as indicated above before their admission. Table I summarises these findings.

The distribution of out-patients over the period is given in Table II where it is seen that 14 per cent subsequently became in-patients.

Table $1 \mathrm{II}$ indicates where out-patients were seen and gives an impression of the work-load imposed on the service.

Table IV shows how these consultations were distributed over the year.

Of the new patients three-hundred and seventy-seven were referred by medical officers. Only thirty-four, ten men and twenty-four women were referred by other departments in B.M.H. or other service hospitals. 
Table $V$ shows the referral rates per thousand of each service population. The rates for females are not shown separately as they closely approximated to each other.

Table I

Out-patients attending

\begin{tabular}{l|c|c|c|c|c|c}
\hline & \multicolumn{2}{|c|}{ Males } & \multicolumn{2}{c|}{ Females } & \multicolumn{3}{c}{ Both sexes } \\
\cline { 2 - 7 } & Number & Per cent & Number & Per cent & Number & Per cent \\
\hline $\begin{array}{l}\text { New out-patients } \\
\text { Out-patients continuing to } \\
\text { attend from before June 1969 }\end{array}$ & 207 & 80.5 & 204 & 67.3 & 411 & 73.6 \\
Discharged in-patients & 29 & 11.3 & 68 & 22.4 & 97 & 17.4 \\
\hline \multicolumn{1}{|c|}{ Totals } & 21 & 8.2 & 31 & 10.3 & 52 & 9.0 \\
\hline
\end{tabular}

Table II

Distribution of patients (percentages)

\begin{tabular}{l|c|c|c}
\hline & Males (257) & Females (303) & Both sexes (560) \\
\hline Out-patient only & 78.6 & 74.9 & 76.8 \\
Out-patient-later in-patient & 13.2 & 14.8 & 14.0 \\
In-patient first-later out-patient & $\mathbf{8 . 2}$ & 10.3 & 9.2 \\
\hline
\end{tabular}

Table III

Place where out-patient consultation took place

\begin{tabular}{l|c|c|r}
\hline & New consultation & Review consultation & Total \\
\hline B.M.H. Singapore & 206 & 340 & 546 \\
R.A.F. Changi & 63 & 139 & 202 \\
H.M.S. "Terror" & 96 & 91 & 187 \\
Penang . Terg (until December 1969) & 27 & 45 & 72 \\
B.M.H. Terendak (un & 19 & 22 & 41 \\
\hline \multicolumn{1}{c|}{ Totals } & 411 & 637 & 1048 \\
\hline
\end{tabular}

Table IV

Distribution of consultations over the year

\begin{tabular}{l|c|c|c}
\multicolumn{1}{c|}{ Month } & Review consultations & New consultations & \multicolumn{2}{c}{ Total } \\
\hline June & 70 & 35 & 105 \\
July & 60 & 57 & 117 \\
August & 24 & 58 & 82 \\
September & 66 & 49 & 115 \\
October & 61 & 28 & 77 \\
November & 57 & 20 & 59 \\
December & 44 & 15 & 72 \\
January & 44 & 28 & 56 \\
February & 37 & 19 & 88 \\
March & 52 & 36 & 103 \\
April & 67 & 36 & 85 \\
May & 55 & 30 & 1048 \\
\hline \multicolumn{1}{c}{ Totals } & 637 & 411 & \\
\hline
\end{tabular}


Table $\mathrm{V}$

Out-patient referral rates per thousand of the population

\begin{tabular}{l|r|c|c}
\multicolumn{1}{c|}{ Category } & Male & Female & Overall \\
\hline Army & $6 / 1000$ & & \\
Navy & $22 / 1000$ & $13 / 1000$ & $9 / 1000$ \\
Air Force & $8 / 1000$ & & \\
Civilian & $5 / 1000$ & & \\
\hline
\end{tabular}

The relatively high rate for the Royal Navy is almost certainly not so much an expression of morbidity, but the result of the excess of unaccompanied ratings in the area and the obvious need for medical officers to seek psychiatric opinion when a rating's behaviour causes anxiety or disruption in a sea-going ship's company.

\section{Diagnosis}

Diagnoses were made as closely as possible in accordance with the Glossary of Mental Disorders, General Register Office 1968. However, to facilitate presentation a more embracing nomenclature has been used in which diagnostic groups are more clearly evident. Table VI shows the principal diagnosis. Any categorisation does violence to the richness of presenting symptomatology and the variety of symptoms and signs offered by each individual patient, initially or over a period of time. For ease of presentation the primary disorder has been used to classify the patients but it must be kept in mind that in almost every case multiple categories of symptoms were the rule.

Table VI gives the diagnostic categories.

Just over a third of the patients were neurotic and almost a tenth were psychotic.

Table VI

Diagnosis of out-patients

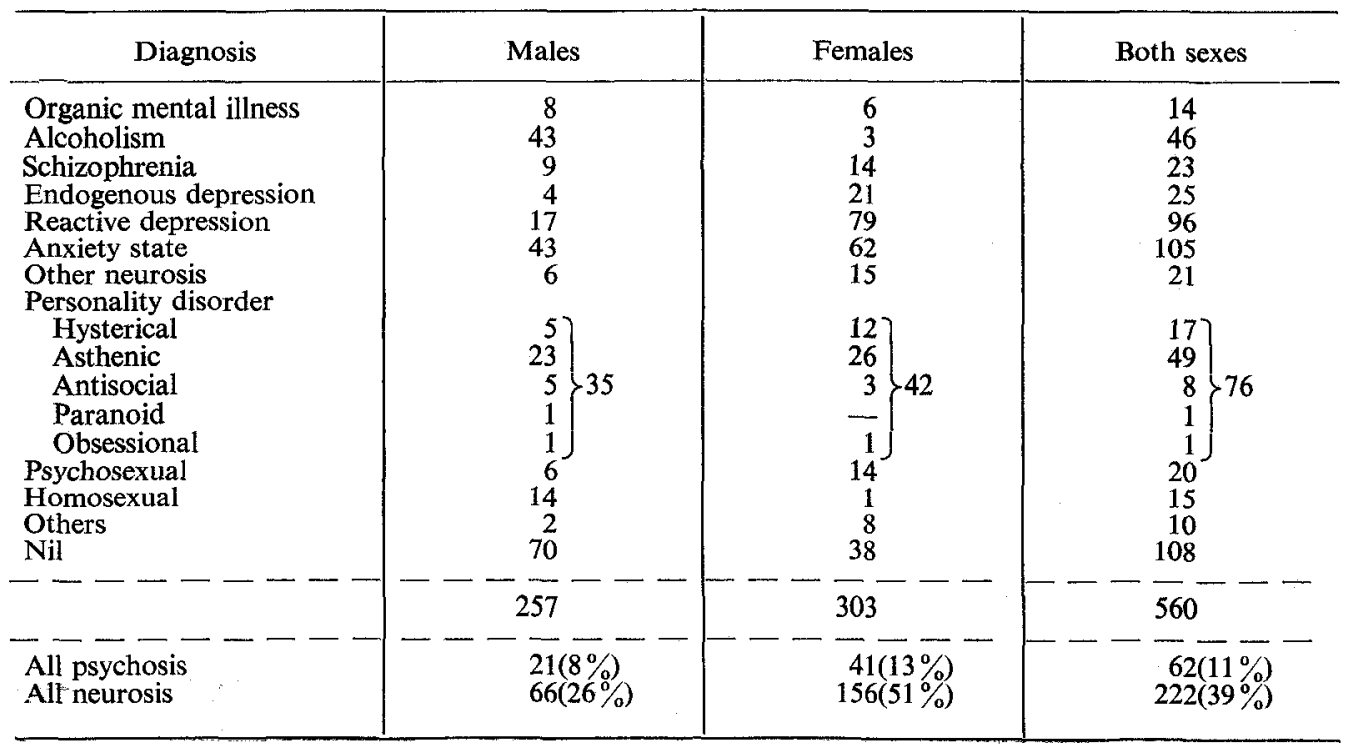


In the neurotic group reactive depression was far more common among women but the usual predominance of anxiety states among men was not found. Within the group of anxiety states two men and thirty women were phobic in nature. The twenty-one cases classified under "Other neurosis" comprised fourteen hysterical neurosis, three neurasthenia, two obsessive compulsive, one hypochondriacal and one paranoid reaction.

Among men alcoholism was of outstanding importance. This point is further emphasised by the fact that abuse of alcohol was of secondary importance in five of the seventeen male reactive depressions and in thirteen of the forty-three male anxiety states. In the group of male personality disorders alcohol played a part in bringing ten out of thirty-five patients to medical notice. Personality disorders were noted in a large proportion of both sexes and formed 14 per cent of all diagnoses. In all, alcohol played a part in the illness of seventy-one male out-patients, 28 per cent.

Under the classification of " nil ", twenty-four of the seventy males were disciplinary cases and twenty of the thirty-eight females were classified as marital problems. Eight females seen for advice on termination of pregnancy are also included in this group.

\section{Treatment and disposal}

Of the four-hundred and eleven new patients eighty were subsequently admitted. Two-hundred and two were returned to their medical officers' care after one consultation and one-hundred and twenty-nine remained under out-patient supervision. Treatment was with drugs or psychotherapy, normally both. Only one patient received electroconvulsive (electric shock) therapy as an out-patient. A small number were referred to service welfare organisations or the marriage guidance service.

\section{In-patient service}

There were two-hundred and seventy-seven admissions to the Wards. Table VII indicates the sources from which they were derived. Direct admissions were usually preceded by telephone conversations with the doctors concerned as were appointments with a view to admission. Cases evacuated from Hong Kong were routed through this department.

Admission rates per thousand of each subdivision of the population are given in Table VIII. In deriving these rates patients from Hong Kong and any patients not permanently based in the area are excluded.

For the Royal Navy rate the reasons may be the same as for out-patients referrals and therefore it is unlikely to be pathologically significant. One should note too that the rate for the Royal Navy dependants is half the rate for Army dependants.

Table IX gives the admission rates per thousand, for the major diagnostic groups, from each subdivision of the population.

The rather high Navy rates of personality disorder and no material psychiatric disorder give more evidence that the Royal Navy figures are functions of unaccompanied drafts and high referral rates by medical officers rather than indices of disease. On the other hand, fourteen of the total of seventeen naval alcoholics were senior ratings who were likely to have been affected by many years of the rum issue, which was not abolished until after the period of this survey. The excess of suicidal behaviour in naval dependants is more than off-set by the strikingly low incidence of other forms of mental disorder. 
Table VII

Sources of in-patients

\begin{tabular}{l|c|c|c}
\hline & Male & Female & Both sexes \\
\hline Out-patient appointments with a view to admission & 54 & 31 & 85 \\
Normal out-patient clinics & 42 & 46 & 88 \\
Direct admissions & 30 & 16 & 46 \\
Transfers from other wards and hospitals & 19 & 20 & 35 \\
In transit from Hong Kong & 160 & 117 & 23 \\
\hline Totals & & & 277 \\
\hline
\end{tabular}

Table VIII

Admission rates per thousand for male and female populations

\begin{tabular}{l|c|c|c}
\hline \multicolumn{1}{c|}{ Male } & Rate & Female & Rate \\
\hline Army & $3.9 / 1000$ & Servicewomen & $4.2 / 1000$ \\
Navy & $9.2 / 1000$ & Dependants of Army & $8.0 / 1000$ \\
Air Force & $3.1 / 1000$ & Navy & $4.1 / 1000$ \\
U.K.B.C. & $2.4 / 1000$ & Air Force & $2.9 / 1000$ \\
& & U.K.B.C. & $4.8 / 1000$ \\
\hline
\end{tabular}

Table IX

Admission rates per thousand for male and female populations by diagnostic groups

\begin{tabular}{|c|c|c|c|c|c|c|c|c|c|}
\hline & \multicolumn{4}{|c|}{ Males } & & \multicolumn{4}{|c|}{ Female (dependants) } \\
\hline & A & B & $\mathrm{C}$ & $\mathrm{D}$ & & A & B & $\mathrm{C}$ & $\overline{\mathrm{D}}$ \\
\hline Alcoholism & 4.8 & 0.9 & 0.5 & 0.5 & Schizophrenia & - & 1.3 & 0.4 & 0.8 \\
\hline Schizophrenia & 0.4 & 1.0 & 0.9 & 1.5 & Endogenous & & 1.0 & & \\
\hline Endogenous & & & & & $\begin{array}{l}\text { depression } \\
\text { Neurosis }\end{array}$ & - & 1.6 & 0.6 & - \\
\hline depression & 0.4 & 0.08 & - & 1.5 & Anxiety & 0.5 & 1.0 & 0.3 & 1.0 \\
\hline $\begin{array}{l}\text { Neurosis } \\
\text { Anxiety }\end{array}$ & 0.8 & 0.5 & 0.6 & - & Depression & 0.6 & 1.2 & 0.5 & - \\
\hline Depression & 0.2 & 0.3 & 0.1 & 0.1 & $\begin{array}{l}\text { Personality } \\
\text { disorders }\end{array}$ & 1.3 & 30 & 11 & 08 \\
\hline $\begin{array}{l}\text { Personality } \\
\text { disorders }\end{array}$ & 4.0 & 0.7 & 0.7 & - & $\begin{array}{l}\text { Suicide } \\
\text { attempts }\end{array}$ & 2.2 & 1.2 & 0.4 & 0.8 \\
\hline N.M.P.D. & 2.0 & 0.8 & 0.3 & - & & & & & \\
\hline
\end{tabular}

$\mathrm{A}=$ Royal Navy. $\mathrm{B}=$ Army. $\mathrm{C}=$ Royal Air Force. $\mathrm{D}=$ United Kingdom Based Civilians.

\section{Diagnosis of in-patients are given in Table X.}

The patients with organic mental illness were all in-patients for a long period, They suffered from presenile dementia, post IZNAH psychosis and a post encephalitic state which presented compulsive movements and visual hallucinations.

The alcoholic patients may be split into the groups indicated in Table XI.

Associated physical damage is indicated in Table XII.

Alcohol played a significant part in the preservation of one schizophrenic, two endogenous depressions, two reactive depressions and four anxiety states. Among the personality disorders it played a part in seventeen out of the thirty-one male cases. 
Table $\mathbf{X}$

Diagnosis of in-patients

\begin{tabular}{|c|c|c|c|}
\hline Diagnosis & Male & Female & Both sexes \\
\hline Organic mental illness & 2 & 1 & 3 \\
\hline Alcoholism & 40 & 1 & 41 \\
\hline Schizophrenia & 24 & 11 & 35 \\
\hline Endogenous depression & 8 & 12 & 20 \\
\hline Reactive depression & 9 & 12 & 21 \\
\hline Anxiety state & 14 & 12 & 26 \\
\hline Other neuroses & 4 & 4 & 8 \\
\hline $\begin{array}{l}\text { Personality disorder } \\
\text { Hysterical personality }\end{array}$ & & & \\
\hline $\begin{array}{l}\text { Hysterical personality } \\
\text { Asthenic }\end{array}$ & $\begin{array}{r}2 \\
18\end{array}$ & $\left.\begin{array}{l}15 \\
13\end{array}\right]$ & - \\
\hline $\begin{array}{l}\text { Asthenic } \\
\text { Antisocial }\end{array}$ & $9 \succ 31$ & $8\} 36$ & $-\zeta 67$ \\
\hline Paranoid & 2 & - & -1 \\
\hline Obsessional & $-j$ & $-\mathrm{J}$ & - \\
\hline Psychosexual & 2 & 1 & 3 \\
\hline Homosexual & 3 & - & 3 \\
\hline $\begin{array}{l}\text { Others } \\
\text { Nil }\end{array}$ & $\begin{array}{r}1 \\
24\end{array}$ & $\begin{array}{r}4 \\
13\end{array}$ & $\begin{array}{r}5 \\
37\end{array}$ \\
\hline Nil $-\cdots-\cdots$ & $--\frac{1}{1 s a}-\cdots$ & ------ & $-\cdots--\cdots$ \\
\hline & 162 & 107 & 269 \\
\hline$-\overline{\text { Total psychosis }}$ & $--\overline{34}-\cdots$ & $--\overline{24}--$ & $58(22 \%)$ \\
\hline Total neurosis & 27 & 28 & $55(21 \%)$ \\
\hline
\end{tabular}

Table XI

Alcoholic in-patients

\begin{tabular}{l|c|c|c}
\hline & \multirow{2}{*}{ Number } & Disposal & \\
\cline { 3 - 4 } & & Returned to unit & Casevacuation \\
\hline $\begin{array}{l}\text { Delirium tremens } \\
\text { Habitual excessive drinking }\end{array}$ & 5 & 1 & 4 \\
Alcoholic addiction & 26 & 11 & 23 \\
\hline
\end{tabular}

Table XII

Associated medical conditions

\begin{tabular}{l|c|l|c}
\hline \multicolumn{1}{c|}{ Condition } & Number & \multicolumn{1}{|c|}{ Condition } & Number \\
\hline Cardiomyopathy & 1 & Alcoholic hepatitis & 1 \\
Peripheral neuropathy & 2 & Withdrawal fits & Dementia \\
Alcoholic cirrhosis & 2 & & 3 \\
\hline Totals & & & $11(26 \%)$ \\
\hline
\end{tabular}

In all, alcohol was a significant factor in sixty-six out of the one-hundred and sixtytwo male admissions.

The schizophrenic group presented a very wide range of symptoms. In those suffering their first attacks of the illness, symptoms had, on average, been present for about three months. All but two of the males were evacuated but females were usually maintained by the department, only two being returned to the United Kingdom. Of the females three had puerperal illnesses and six were chronic schizophrenics. The average length of stay in hospital was twenty-four days. 
In the groups of endogenous depressions, two of the females were in fact cases of Involutional Melancholia. The average age of the male patients was 46 years and the female 33 years. In three female cases the illness occurred in the Puerperium. Three males and two females were returned to the United Kingdom. The average length of stay in hospital was thirty-three days.

Neurotic patients admitted to the wards represent the numbers of severe and disabling neurosis occurring in the population. The average length of stay in hospital for reactive depression and anxiety states was fourteen days. The association between male neurosis and alcohol has been mentioned above. Over half the male patients were casevacuated but only five females were so managed. Included under the heading of other neurosis are obsessional, hysterical and hypochondriacal cases and two paranoid reactions.

The large group of personality disorders reflects the youth of the population. Only those classified as antisocial were returned to Britain with any frequency, nine out of seventeen. It is convenient here to consider attempted suicide as a reason for admission. Table XIII gives the number concerned.

Table XIII

Attempted suicide

\begin{tabular}{l|c|c}
\hline & Male & Female \\
\hline Schizophrenia & 1 & - \\
Personality disorder & 3 & 12 \\
Transient situation distress & 3 & 3 \\
\hline \multicolumn{1}{|c|}{ Totals } & 7 & 15 \\
\hline
\end{tabular}

No cases were seen either as in or out-patients of underlying depression. To give a more reliable impression of the department's experience; eleven women seen as outpatients while on other wards, and two men, should be added to the group classified as transient situational disturbance. Only two methods were seen, wrist slashing and drug overdose. All but one man cut his wrists, the exception was the schizophrenic patient who took an overdose of Chloroquine and all but two women took a drug overdose, most commonly of Aspirin followed by tranquillizers and barbiturates.

In the group with psychosexual disorders are included a transvestite, a sadomasochist and a sadist. The homosexuals who became in-patients all showed marked anxiety features and one also abused alcohol as a result of this. Among the patients recorded as other diagnoses were two cases of anorexia nervosa and three of drug dependence. One of these dependent on barbiturates had a withdrawal fit. To complete the picture of drug dependence four out-patients used marijuana and four females were dependent on barbiturates.

\section{Treatment and Management}

Table XIV shows the disposal of all in-patients over the year.

All in-patients were given a physical examination and had a blood count, urine analysis, V.D.R.L., chest and skull $\mathrm{X}$-rays as a routine. Further investigations were performed as indicated. Lumbar puncture was performed on ten occasions. 
Table XIV

Disposal of Patients

\begin{tabular}{l|c|c|c}
\hline & Males & Females & Total \\
\hline $\begin{array}{l}\text { Returned to unit/home } \\
\text { Casevacuation }\end{array}$ & $\begin{array}{l}75 \\
78(51 \%)\end{array}$ & $\begin{array}{l}90 \\
21(34 \%)\end{array}$ & $\begin{array}{c}165 \\
99(34 \%)\end{array}$ \\
\hline
\end{tabular}

Psychotherapy was given to all patients and the great majority also received drugs. The range of commonly used drugs was small and included Largactil, Stelazine, Artane, Amitriptyline, Nortriptyline, Valium, Librium and Mogadon. For alcoholic withdrawal states a Librium reducing regime allied with intramuscular Parantrovite was used.

Electroplexy was given on two-hundred and sixty-two occasions to forty-two patients. The normal routine was two per week. Of other physical treatments, Modified Narcosis was used three times and Insulin Sopor twice. In the case of Modified Narcosis two of the patients suffered complications, one developed acute agranulocytosis and the other a Deep Vein Thrombosis.

Narco-analysis using intravenous Na.Amytal was used on four occasions. Psychotherapy was predominantly explanatory and supportive, based on an electic approach. Therapy using Reciprocal Inhibition was given to four patients with apparently isolated phobias. In one case a successful result was obtained but treatment in the other three was unsuccessful because of personality factors.

\section{Child Guidance Service}

This part of the service is to be the subject of a detailed paper at present in preparation and a brief note only is included for the sake of completeness.

Over the period under consideration 185 children were referred, an average of 15 per month. Initially the educational authorities were the main source but as the year progressed an ever increasing proportion were referred from medical sources. The referral rate was of the order of 8 per thousand children in the catchment area.

The work-load of this subspeciality is indicated by the fact that 353 consultations were given and in all 524 parents were also seen.

\section{Conclusion}

Although no statistical tests of significance have been carried out and no conclusions can be drawn from the inter-Service comparisons, it is hoped the survey will provide "food for thought". Taken overall it demonstrates certain features of service psychiatry. The limited age range is well reflected in the proportions of diagnostic categories. The referral rates for out-patients are of the same order as those published for civilian practice for the age groups 15 to 45 years. Kessel and Hassall (1965) give referral rates of 7/1000 males and 9/1000 females. However in the service population there is a much higher proportion of cases diagnosed as personality disorder or no material psychiatric disability and proportionately fewer assessed as psychotic or neurotic than in civilian studies, which cover the full range of the population. 
As a result of this distribution fewer out-patients are eventually admitted, than in civilian practice, although one would like to feel that this is to some extent due to the emphasis placed in maintaining the patient in the community.

The incidence of psychosis is the same as in the general population and this is well seen in the in-patient study. As compared to the closest civilian institution to this department, the " observation ward", there is greater incidence of neurosis and again diagnosis of personality disorder or no material psychiatric disability.

Throughout the paper as a whole, the peculiar significance of alcohol in service psychiatry has been demonstrated, and emphasised, both in patients out of hospital and on the Ward.

\section{REFERENCE}

Kessell, N. and Hassell, H. (1965). Brit. J. Psychiat. 3, 470.

\section{Honorary Consultants}

The following have been appointed Honorary Consultants to the Army, with effect from the dates shown:

\section{Honorary Consultants in Surgery}

Professor A. J. Harding Rains, M.S., F.R.C.S. and Mr. Rodney Smith, M.S., F.R.C.S., with effect from 1 April 1972.

\section{Honorary Consultant Physicians}

Dr. F. D. Hart, M.D., F.R.C.P. and Dr. T. A. Kemp, M.D., F.R.C.P., with effect from 21 February 1972.

\section{Order of St. John of Jerusalem}

Those recently appointed to, or promoted in, the Most Venerable Order of the Hospital of St. John of Jerusalem include:

As Commander (Brother)

Major-General J. P. Baird, Q.H.P.

As Officer (Brother)

Brigadier E. D. H. Stanhope, M.B.E. Colonel H. W. Whitcher, O.B.E., T.D., Lieutenant-Colonels F. J. Hebbert, E.R.D., R. K. Levick, T.D., W. C. Moffat, P. Stewart and W. G. Thomson. Majors N. A. Boyd and C. H. J. Chevis. 